\title{
(- OPEN ACCESS \\ Leaky pipeline, gender bias, self-selection or all three? \\ A quantitative analysis of gender balance at an international palliative care research conference
}

\author{
Katherine E Sleeman, Jonathan Koffman, Irene J Higginson
}

Department of Palliative Care, Policy and Rehabilitation, King's College London-Cicely Saunders Institute, London, UK

\section{Correspondence to} Dr Katherine E Sleeman, Department of Palliative Care, Policy and Rehabilitation, King's College London-Cicely Saunders Institute, London, UK; katherine.sleeman@kcl.ac.uk

Received 28 July 2016 Revised 22 November 2016 Accepted 26 January 2017 Published Online First

7 March 2017

\section{Check for updates}

To cite: Sleeman KE, Koffman J, Higginson IJ. BMJ Supportive \& Palliative Care 2019;9:146-148.

\section{ABSTRACT}

Objectives The 'leaky pipeline' in academia is a clearly described phenomenon, but has not been examined in palliative care. We analysed the gender balance of speakers at the 9th World Research Congress of the European Association of Palliative Care (EAPC) to test the null hypothesis that there is no difference in the proportion of women and men with senior academic visibility in palliative care conference programmes.

Methods The final programme of the 2016 EAPC World Congress was examined, and the gender of each speaker was recorded. Presentations were assessed using a three-tier hierarchy of senior academic visibility: Free Communication sessions, Themed sessions and invited Plenaries (low to high). As there was only one Invited Plenary at EAPC 2016, we examined the gender balance at EAPC Plenaries from 2012 to 2016.

Results Overall, the majority of speakers at EAPC 2016 (96/130, 73.8\%) were women. The proportion of women was highest in the Free Communication sessions (84/107, 78.5\%). In the Themed sessions, women made up just over half of speakers (12/22, 54.5\%). In 2016, there was 1 invited Plenary speaker, a man. From 2012 to 2016, just 6 of 23 invited Plenary speakers at EAPC conferences have been women (26.1\%) $\left(\chi^{2}=25.4, p<0.001\right)$.

Conclusions These data reject our null hypothesis and suggest that there is attrition of women along the academic pipeline in palliative care. Other factors such as self-selection (that women decline invitations to give talks) and unconscious gender bias need further exploration, as well as actions to address the imbalance.

\section{INTRODUCTION}

The gender balance in academia is the subject of considerable debate. ${ }^{1-3}$ The progress of women through academia has been described as a 'leaky pipeline', where there is attrition of women at each step of the career ladder. Initiatives to redress this are gaining momentum, for example the UK Athena SWAN Charter which was established in 2005 to encourage and recognise commitment to advancing the careers of women in science, technology, engineering, maths and medicine (STEMM).

Visibility, for example through conference talks and plenaries, is an important dimension of gender equality. A paucity of women conference speakers has been demonstrated in several academic disciplines. ${ }^{4}$ However, it is unclear if the same phenomenon exists in palliative care, a specialty where women traditionally make up the majority of the workforce. ${ }^{5}$

In June 2016, 1200 delegates attended the 9th World Research Congress of the European Association of Palliative Care (EAPC) in Dublin, making it one of the largest research conferences in palliative care globally. The programme featured 17 Free Communication sessions where researchers were chosen on the quality of anonymous (and gender-blind) abstracts to present their work in $8 \mathrm{~min}$ talks. In addition, there were seven Themed sessions in which speakers were invited on the basis of their level of authority on a specific subject to give $20 \mathrm{~min}$ talks. The most prestigious speaking opportunity is the invited Plenary where high-profile 
academics are invited to give longer talks $(30 \mathrm{~min})$ on the main conference stage.

We aimed to analyse the gender balance of speakers at the 2016 EAPC World Congress to test the null hypothesis that there is no attrition of women in senior academic positions in palliative care, using the three-tiered hierarchy of Free Communication sessions, Themed sessions and Plenaries as a proxy for seniority.

\section{METHODS}

The final programme of the 2016 EAPC World Congress was examined, and the gender of each speaker was recorded. Speaker gender was determined either by direct observation of their talk or by inference from their first name. In eight cases, Google was used for more information. Where there was a substitution of speaker at the last minute, the gender of the speaker originally planned was used. At the 2016 EAPC, five top scoring abstracts were presented as 15 min Plenaries on the main stage. Since the decision to feature these presentations was made on the basis of an anonymous abstract, these were analysed with the Free Communication sessions. Since there was only one invited Plenary speaker at 2016 EAPC, we examined the gender balance of invited EAPC Plenary speakers over 5 years $(2012-2016)$ by searching through relevant scientific programmes online. $\chi^{2}$ tests were used to assess differences. We did not analyse Meet the Expert sessions or Poster Discussion sessions.

\section{RESULTS}

At EAPC 2016, there were a total of 17 Free Communication sessions comprising 102 talks. An additional five top scoring abstracts were presented on the main stage. There were seven Themed sessions which included 22 speakers. There was a single invited Plenary, the Ventafridda Lecture.

Overall, the majority of speakers at EAPC 2016 were women. The proportion of women was highest in the Free Communication sessions. In the Themed sessions, women made up just over half of speakers. The Ventafridda Lecture was given by a man (table 1).

Since there was only one invited Plenary speaker at EAPC 2016, we examined previous EAPC conference programmes to obtain a more representative view of

Table 1 Men and women giving talks at EAPC 2016, according to session type

\begin{tabular}{lcc}
\hline & Men (\%) & Women (\%) \\
\hline Invited plenary & $1(100)$ & $0(0)$ \\
Themed session & $10(45.5)$ & $12(54.5)$ \\
Free communication & $23(21.5)$ & $84^{*}(78.5)$ \\
Total & $34(26.2)$ & $96(73.8)$ \\
\hline
\end{tabular}

*Includes five top scoring abstracts presented on the main stage. gender balance of invited Plenary speakers for a 5 -year period (figure 1). At EAPC 2015, there were eight invited Plenary speakers (including a debate), of whom two were women (25\%). At EAPC 2014, there were two Plenary speakers, both men. At EAPC 2013, there were nine Plenary speakers, including three women (33.3\%). At EAPC 2012, one of three Plenary speakers was a woman (33.3\%). Taking 5 years together, 6 of 23 invited Plenary speakers at EAPC conferences have been women $(26.1 \%) \quad\left(\chi^{2}=25.4\right.$, $\mathrm{p}<0.001)$.

\section{DISCUSSION}

Palliative care is a profession where women make up the majority of the workforce, ${ }^{5}$ and this is reflected in the overall gender balance of those giving talks at EAPC 2016. However, we identified that the proportion of women is lower for invited talks compared to those chosen anonymously from abstracts: whereas around three quarters of speakers in the Free Communication sessions were women, this proportion reduced to roughly half for the Themed sessions, and to only a quarter for the invited Plenaries (using pooled data from 2012 to 2016).

Given the large number of women working in palliative care, it is of concern that the most prestigious invited Plenaries are so infrequently given by women, and it is noteworthy that two EAPC conferences over the past 5 years have included no female Plenary speakers at all (2014 and 2016). These data suggest that there is attrition of women along the academic pipeline' in palliative care. However, the relative contribution of other potential factors such as selfselection (that women decline invitations to give talks) and unconscious gender bias (that women are not invited to give talks) is unclear. In addition, palliative care is multiprofessional, with gender unequally represented within each of the professions. The potential contribution of discipline should also be explored.

Given that there was a single Plenary speaker in 2016, we examined the gender balance of Plenary speakers over 5 years. This was based on the assumption that variation from conference to conference is likely to outweigh any temporal trends. The proportion of female Plenary speakers was one-third or fewer for each of the 5 years examined. There was no indication that the proportion of female Plenary speakers improved over time. Indeed, the 2012 and 2013 conferences had the greatest proportion of female Plenary speakers (one-third).

Speaking at academic conferences is important for career advancement. Such opportunities not only facilitate networking and collaboration, but are used as a marker of quality by promotions panels. ${ }^{6}$ Strategies to improve the proportion of women invited to speak, particularly those invited to give Plenaries, should be explored. These include consideration of the gender balance on scientific organising 


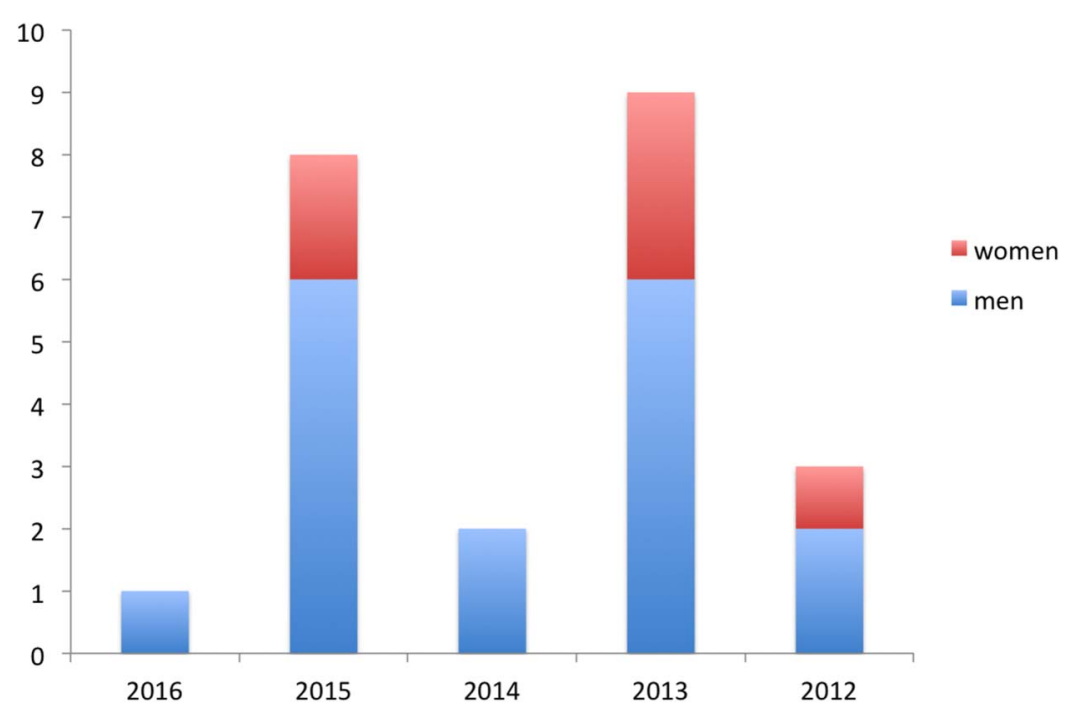

Figure 1 Number of men and women giving invited Plenaries, 2012-2016.

committees, as the proportion of women on convening panels has been shown to be correlated with the proportion of women speakers. ${ }^{4} 6$ The issue of selfselection is important: previous studies have shown that women are more likely than men to decline invitations to speak at conferences, ${ }^{7}$ and less likely than men to put themselves forward for talks. ${ }^{8}$ These issues should be explored and addressed, for example through routine collection and analysis of the gender of all authors who submit abstracts, not only for EAPC Congresses but for all major palliative care conferences. Scientific organising committees should scrutinise information on invitations, acceptances and refusals for high-profile speaking positions. Where women decline invitations to speak, the reasons for this should be explored, and steps to increase future acceptance rates identified. These initiatives will help us to understand the relative contributions of lack of assertiveness and lack of recognition. In addition, routinely collecting feedback from delegates on the issue of gender equality might identify hidden issues. Last, we suggest that explicit acknowledgement of low visibility of female speakers by conference organisers may itself act as an intervention to redress the balance.

Failure of promotion on merit is deleterious for academia and ultimately for patient care. Whether these data represent a leaky pipeline, gender bias, selfselection or all three, it is essential that as a specialty we take this issue seriously. We hope that the data presented here provide a starting point for more in-depth consideration of this issue and appropriate strategies to tackle it.

Contributors KES conceived and designed this study, performed the analysis and wrote the manuscript, with help from IJH and JK throughout.

Funding KES is funded by an NIHR Clinician Scientist Fellowship and has received funding from Cicely Saunders International. No specific funding was received for this study.
Competing interests IJH was Chair of the Scientific Organising Committee of the 2015 EAPC World Congress in Copenhagen and gave an invited Plenary at the 2012 EAPC Research Congress in Trondheim. KES, JK and IJH are members of the King's College London Department of Palliative Care Athena SWAN Self-Assessment Team.

Provenance and peer review Not commissioned; externally peer reviewed.

Open Access This is an Open Access article distributed in accordance with the terms of the Creative Commons Attribution (CC BY 4.0) license, which permits others to distribute, remix, adapt and build upon this work, for commercial use, provided the original work is properly cited. See: http://creativecommons.org/licenses/by/4.0/

\section{REFERENCES}

1 Moss-Racusin CA, Dovidio JF, Brescoll VL, et al. Science faculty's subtle gender biases favor male students. Proc Natl Acad Sci USA 2012;109:16474-9.

2 Edmunds LD, Ovseiko PV, Shepperd S, et al. Why do women choose or reject careers in academic medicine? A narrative review of empirical evidence. Lancet 2016;388:2948-58.

3 Handley IM, Brown ER, Moss-Racusin CA, et al. Quality of evidence revealing subtle gender biases in science is in the eye of the beholder. Proc Natl Acad Sci USA 2015;112:13201-6.

4 Isbell LA, Young TP, Harcourt AH. Stag parties linger: continued gender bias in a female-rich scientific discipline. PLOS ONE 2012;7:e49682.

5 NCPC Specialist Palliative Care (SPC) Workforce Survey 2013. http://www.ncpc.org.uk/sites/default/files/NCPC_SPC_Workforce_ Survey_2013.pdf (accessed 6 February 2017)

6 Casadevall A. Achieving speaker gender equity at the American Society for Microbiology General Meeting. mBio 2015;6:e01146.

7 Schroeder J, Dugdale HL, Radersma R, et al. Fewer invited talks by women in evolutionary biology symposia. J Evol Biol 2013;26:2063-9.

8 Jones TM, Fanson KV, Lanfear R, et al. Gender differences in conference presentations: a consequence of self-selection? PeerJ 2014;2:e627. 